\title{
MAGNETOHYDRODYNAMIC FREE CONVECTION AND MASS TRANSFER FLOW PAST A VERTICAL POROUS FLAT PLATE WITH DUFOUR AND SORET EFFECTS
}

\author{
Md. Abdul Maleque ${ }^{1}$ and Md. Shariful Alam ${ }^{2}$ \\ ${ }^{1}$ Department of Mathematics, Bangladesh University of Engineering and Technology (BUET), Dhaka- \\ 1000, Bangladesh. Email: amaleque@math.buet.ac.bd \\ ${ }^{2}$ Department of Mathematics, Dhaka University of Engineering and Technology (DUET), Gazipur- \\ 1700, Bangladesh. Email: msalam631@yahoo.com
}

\begin{abstract}
An analysis of free convection and mass transfer unsteady magnetohydrodynamic flow of an electrically conducting viscous incompressible fluid past an infinite vertical porous plate is presented by taking into account the Dufour and Soret effects. With a goal to attain similarity solutions of the problem posed, similarity equations are derived by introducing a time dependent length scale. The non-linear similarity equations, which are locally similar, are solved numerically using shooting method. Dimensionless velocity, temperature and concentration profiles are displayed graphically for different values of the parameters entering into the problem. Finally, the corresponding local skin-friction, local Nusselt number and local Sherwood number, which are of physical interest are tabulated.
\end{abstract}

Keywords: Magnetodydrodynamic, Free convection, Mass transfer, Dufour and Soret effects.

\section{NOMENCLATURE:}

\begin{tabular}{|c|c|c|c|}
\hline$B_{0}$ & Applied magnetic field & $T$ & Temperature \\
\hline$C$ & Concentration & $T_{m}$ & Mean fluid temperature \\
\hline$C_{p}$ & Specific heat at constant pressure & $U_{0}$ & Constant plate velocity \\
\hline$C_{s}$ & Concentration susceptibility & $u, v$ & Velocity components in $x$ and $y$ direction \\
\hline$D f$ & Dufour number & & respectively \\
\hline$D_{m}$ & Mass diffusivity & $x, y$ & Cartesian coordinates along the plate and \\
\hline$f$ & Dimensionless velocity & & normal to it, respectively \\
\hline$g$ & Acceleration due to gravity & $\alpha$ & Thermal diffusivity \\
\hline$G r$ & Local temperature Grashof number & $\beta$ & Coefficient of thermal expansion \\
\hline$G m$ & Local mass Grashof number & $\beta^{*}$ & Coefficient of concentration expansion \\
\hline $\operatorname{Pr}$ & Prandtl number & $\sigma$ & Electrical conductivity \\
\hline$S c$ & Schmidt number & & Density of the fluid \\
\hline $\mathrm{Sr}$ & Soret number & $\rho$ & Kinematic viscosity \\
\hline$S h$ & Sherwood number & $\begin{array}{l}\mathcal{U} \\
\theta\end{array}$ & Dimensionless temperature \\
\hline$N u$ & Nusselt number & $\theta$ & Dimensionless concentration \\
\hline$M$ & Magnetic parameter & $\phi$ & Condition at wall \\
\hline$k_{T}$ & Thermal diffusion ratio & $w$ & \\
\hline
\end{tabular}

\section{Introduction:}

The phenomenon of free convection has many important technological applications such as in cooling a nuclear reactor and providing heat sinks turbine blades. In recent year, the subject of free convection has attracted many authors in view not only of its own interest but also of the applications to astrophysics and engineering. Soundalgekar (1977) studied the free convection flow past an 
impulsively started infinite vertical plate, when it is cooled or heated by the free convection currents. Kafoussias et al. (1979) studied the effects of suction on the flow field, in the above problem. Nanousis et al. (1980) extended this problem to magnetohydrodynamics.

In all the above studies, the Dufour and Soret effects were neglected on the basis that they are of a smaller order of magnitude than the effects described by Fourier's and Fick's laws. However, exceptions are observed therein. The thermal-diffusion (Soret) effect, for instance, has been utilized for isotope separation, and in mixture between gases with very light molecular weight $\left(\mathrm{H}_{2}, \mathrm{He}\right)$ and of medium molecular weight $\left(\mathrm{N}_{2}\right.$, air) the diffusion-thermo (Dufour) effect was found to be of order of considerable magnitude such that it cannot be ignored [Eckert and Drake(1972)]. In view of the importance of this diffusion-thermo effect, Jha and Singh (1990) studied the free-convection and mass transfer flow about an infinite vertical flat plate moving impulsively in its own plane, taking into account the Soret effects. Kafoussias (1992) studied the same problem in the case of MHD flow. Recently, Kafoussias and Williams (1995) studied thermal-diffusion and diffusion-thermo effects on mixed free-forced convective and mass transfer boundary layer flow with temperature dependent viscosity.

Consequently the aim of the present work is to investigate the thermal-diffusion (Soret) and diffusionthermo (Dufour) effects on magnetohydrodynamic free convection and mass transfer flow past an infinite vertical porous flat plate with variable suction and constant viscosity.

\section{Mathematical analysis:}

We consider two-dimensional, unsteady, magnetohydrodynamic, free convection and mass transfer flow, of a viscous incompressible and electrically conducting fluid past an infinite vertical porous flat plate. The $x$-axis is taken along the plate in the upward direction and the $y$-axis normal to it. A magnetic field of uniform strength is applied transversely to the direction of the flow. The induced magnetic field can be neglected since the magnetic Reynolds number of the flow is assumed very small. The fluid properties are also assumed to be constant in a limited temperature range except for the influence of the density variations with temperature and concentration, which are considered only in the body force term. Under the above assumptions, the physical variables are functions of $y$ and $t$ only and therefore the basic equations relevant to the problem are:

Continuity equation

$$
\frac{\partial v}{\partial y}=0
$$

Momentum equation

$$
\frac{\partial u}{\partial t}+v \frac{\partial u}{\partial y}=v \frac{\partial^{2} u}{\partial y^{2}}+g \beta\left(T-T_{\infty}\right)+g \beta^{*}\left(C-C_{\infty}\right)-\frac{\sigma B_{0}^{2} u}{\rho}
$$

Energy equation

$$
\frac{\partial T}{\partial t}+v \frac{\partial T}{\partial y}=\alpha \frac{\partial^{2} T}{\partial y^{2}}+\frac{D_{m} k_{T}}{c_{s} c_{p}} \frac{\partial^{2} C}{\partial y^{2}}
$$

Concentration equation

$$
\frac{\partial C}{\partial t}+v \frac{\partial C}{\partial y}=D_{m} \frac{\partial^{2} C}{\partial y^{2}}+\frac{D_{m} k_{T}}{T_{m}} \frac{\partial^{2} T}{\partial y^{2}}
$$

with initial and boundary conditions:

$$
\begin{aligned}
& \text { for } t \leq 0: u=v=0, T=T_{\infty}, C=C_{\infty} \text { for all } y \\
& \text { for } t>0 \text { : } \\
& u=0, v=v(t), T=T_{w}, C=C_{w} \text { at } y=0 \\
& u=0, v=0, T=T_{\infty}, C=C_{\infty} \quad \text { as } y \rightarrow \infty
\end{aligned}
$$

where the variables and related quantities are defined in the Nomenclature. 
The last term on the right-hand side of the energy equation (3) and concentration equation (4) signifies the Dufour or diffusion-thermo effect and the Soret or thermal-diffusion effect, respectively.

Now in order to obtain a local similarity solution of the problem under consideration, we introduce a time dependent length scale $\delta$ as

$\delta=\delta(t)$.

In terms of this length scale, a convenient solution of the equation (1) is considered to be in the following form:

$v=v(t)=v_{0} \frac{v}{\delta}$,

where $v_{0}$ is the suction velocity at the plate and the negative sign indicates that the suction velocity is directed towards the plate.

Now, in order to non-dimensionalize equations (2), (3) and (4) the following dimensionless quantities are introduced:

$\eta=\frac{y}{\delta}, G r=\frac{g \beta\left(T_{w}-T_{\infty}\right) \delta^{2}}{v U_{0}}$ (Grashof number),

$u=U_{0} f(\eta), G m=\frac{g \beta^{*}\left(C_{w}-C_{\infty}\right) \delta^{2}}{v U_{0}}$ (Modified Grashof number),

$\theta(\eta)=\frac{T-T_{\infty}}{T_{w}-T_{\infty}}, D f=\frac{D_{m} k_{T}\left(C_{w}-C_{\infty}\right)}{c_{s} c_{p} v\left(T_{w}-T_{\infty}\right)}$ (Dufour number),

$\phi(\eta)=\frac{C-C_{\infty}}{C_{w}-C_{\infty}}, S r=\frac{D_{m} k_{T}\left(T_{w}-T_{\infty}\right)}{v T_{m}\left(C_{w}-C_{\infty}\right)}$ (Soret number),

$S c=\frac{v}{D_{m}}$ (Schmidt number), $M=\frac{\sigma B_{0}^{2} \delta^{2}}{v \rho}$ (Magnetic parameter)

and $\operatorname{Pr}=\frac{v}{\alpha}$ (Prandtl number).

In view of (7) and (8) equations (2), (3) and (4) become

$f^{\prime \prime}+\eta\left(\frac{\delta}{v} \frac{d \delta}{d t}\right) f^{\prime}+v_{0} f^{\prime}+G r \theta+G m \phi-M f=0$

$-\eta\left(\frac{\delta}{v} \frac{d \delta}{d t}\right) \theta^{\prime}-v_{0} \theta^{\prime}=\frac{1}{\operatorname{Pr}} \theta^{\prime \prime}+D f \phi^{\prime \prime}$

$-\eta\left(\frac{\delta}{v} \frac{d \delta}{d t}\right) \phi^{\prime}-v_{0} \phi^{\prime}=\frac{1}{S c} \phi^{\prime \prime}+S r \theta^{\prime \prime}$

where primes denote differentiation with respect to $\eta$.

The corresponding boundary conditions for $t>0$ are obtained as:

$f=0, \theta=1, \phi=1 \quad$ at $\eta=0$

$f=0, \theta=0, \phi=0 \quad$ as $\eta \rightarrow \infty$

Now the equations (9) - (11) are locally similar except the term $\left(\frac{\delta}{v} \frac{d \delta}{d t}\right)$, where t appears explicitly. Thus the local similarity condition requires that $\left(\frac{\delta}{v} \frac{d \delta}{d t}\right)$ in the equations (9)-(11) must be a constant quantity.

Hence following the works of Hasimoto (1957), Sattar and Hossain (1992) and Sattar (1993), one can try a class of solutions of the equations (9) - (11) by assuming that

$\left(\frac{\delta}{v} \frac{d \delta}{d t}\right)=k$ (a constant $)$ 
Integrating (13) we have

$\delta=\sqrt{2 k v t}$,

where the constant of integration is determined through the condition that $\delta=0$ when $t=0$. From (14) choosing $k=2$, the length scale $\delta(t)=2 \sqrt{v t}$ which exactly corresponds to the usual scaling factor for various unsteady boundary layer flows [Schlichting (1968)]. Since $\delta$ is a scaling factor as well as a similarity parameter, any value of $k$ in (13) would not change the nature of the solutions except that the scale would be different.

Now introducing (13) [with $k=2$ ] in the equations (9) - (11) respectively, we obtain the following dimensionless ordinary differential equations which are locally similar.

$$
\begin{aligned}
& f^{\prime \prime}+\left(2 \eta+v_{0}\right) f^{\prime}+G r \theta+G m \phi-M f=0 \\
& \theta^{\prime \prime}+\operatorname{Pr}\left(2 \eta+v_{0}\right) \theta^{\prime}+\operatorname{Pr} D f \phi^{\prime \prime}=0 \\
& \phi^{\prime \prime}+\operatorname{Sc}\left(2 \eta+v_{0}\right) \phi^{\prime}+\operatorname{ScSr} \theta^{\prime \prime}=0
\end{aligned}
$$

Subject to the reduced boundary conditions follow from (12)

$$
\begin{aligned}
& f=0, \theta=1, \phi=1 \quad \text { at } \eta=0 \\
& f=0, \theta=0, \phi=0 \quad \text { as } \eta \rightarrow \infty
\end{aligned}
$$

The set of equations (15) - (17) together with the boundary conditions (18) are solved numerically by applying Nachtsheim-Swigert (1965) shooting iteration technique along with Runge-Kutta sixth-order integration method. From the process of numerical computation, the skin-friction coefficient, the local Nusselt number and the local Sherwood number, which are respectively proportional to $f^{\prime}(0)$, $-\theta^{\prime}(0)$ and $-\phi^{\prime}(0)$, are also sorted out and their numerical values are presented in tabular form.

\section{Results and Discussion:}

Numerical calculations have been carried out for different values of $v_{0}, M, S r$ and $D f$ and for fixed values of $P r, S c, G r$ and $G m$. The values of $G r$ and $G m$ are taken to be both positive and negative, since these values represent respectively cooling and heating of the plate. The value of Prandtl number $(P r)$ is taken to be 0.71 , which corresponds to air, and the value of Schmidt number $(S c)$ is chosen to represent hydrogen at $25^{\circ} \mathrm{C}$ and $1 \mathrm{~atm}$. The values of Dufour number $\mathrm{Df}$ and Soret number $\mathrm{Sr}$ are chosen in such a way that their product is constant provided that the mean temperature $T_{m}$ is kept constant as well. However, the values of $v_{0}$ and $M$ are chosen arbitrarily. The numerical results for the velocity, temperature and concentration profiles are displayed in Figs. 1 - 6. The effects of suction and magnetic parameters in the velocity field are shown in Fig. 1 for both cooling and heating of the plate. It is seen from this figure that the velocity decreases with the increase of both suction and magnetic parameters for cooling of the plate. In Fig. 2, the effects of Soret and Dufour number are shown for both cooling and heating of the plate. Quantitatively, when $\eta=0.45$ and $S r$ decreases from 2 to 1 (or $D f$ increases from 0.03 to 0.06 ), there is $8.33 \%$ decrease in the velocity value, whereas the corresponding decrease is $2.77 \%$, when $\mathrm{Sr}$ decreases from 1 to 0.5 . In all the figures mentioned above, compared to the case of cooling of the plate opposite effects are observed in the case of heating of the plate.

The temperature profiles are shown in Figs. 3 and 4 for cooling of the plate. In Fig. 3 we see that the temperature decreases with the increase of suction parameter. From Fig. 4 when $\eta=0.50$ and $S r$ decreases from 2 to 1 (or $D f$ increases from 0.03 to 0.06 ), there is $68.77 \%$ increase in the temperature value, whereas the corresponding increase is $33.79 \%$, when $S r$ decreases from 1 to 0.5 .

In Figs. 5 and 6, the concentration profiles are shown for cooling of the plate. It is observed from Fig. 5 that the velocity increases with the increase of suction parameter close to the wall (approx. $\eta<0.62$ ) whereas for $\eta>0.62$, the concentration decreases with the increase of suction parameter. From Fig. 6, when $\eta=0.50$ and $S r$ decreases from 2 to 1 (or $D f$ increases from 0.03 to 0.06 ), there is $19.73 \%$ decrease in the concentration value, whereas the corresponding decrease, when $\mathrm{Sr}$ decreases from 1 to 0.5 , is $10.15 \%$. 


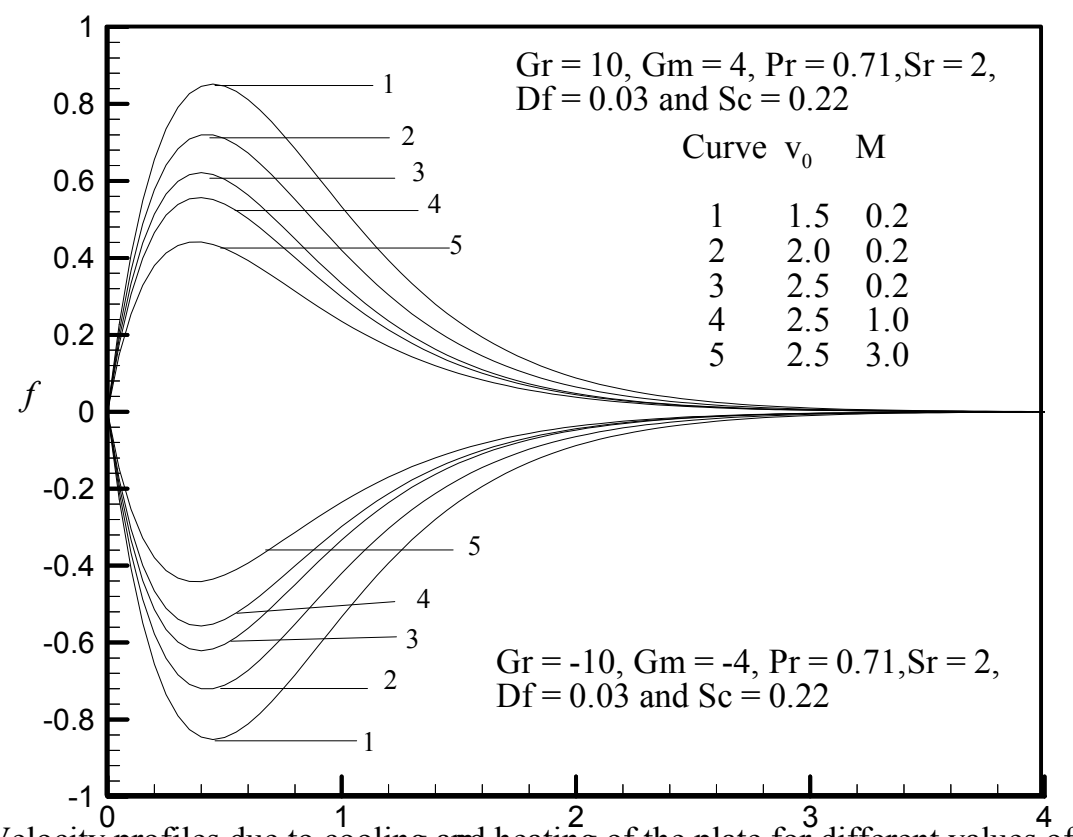

Fig. 1: Velocity profiles due to cooling amd heating of the plate for different values of $v_{0}$ and $M$.

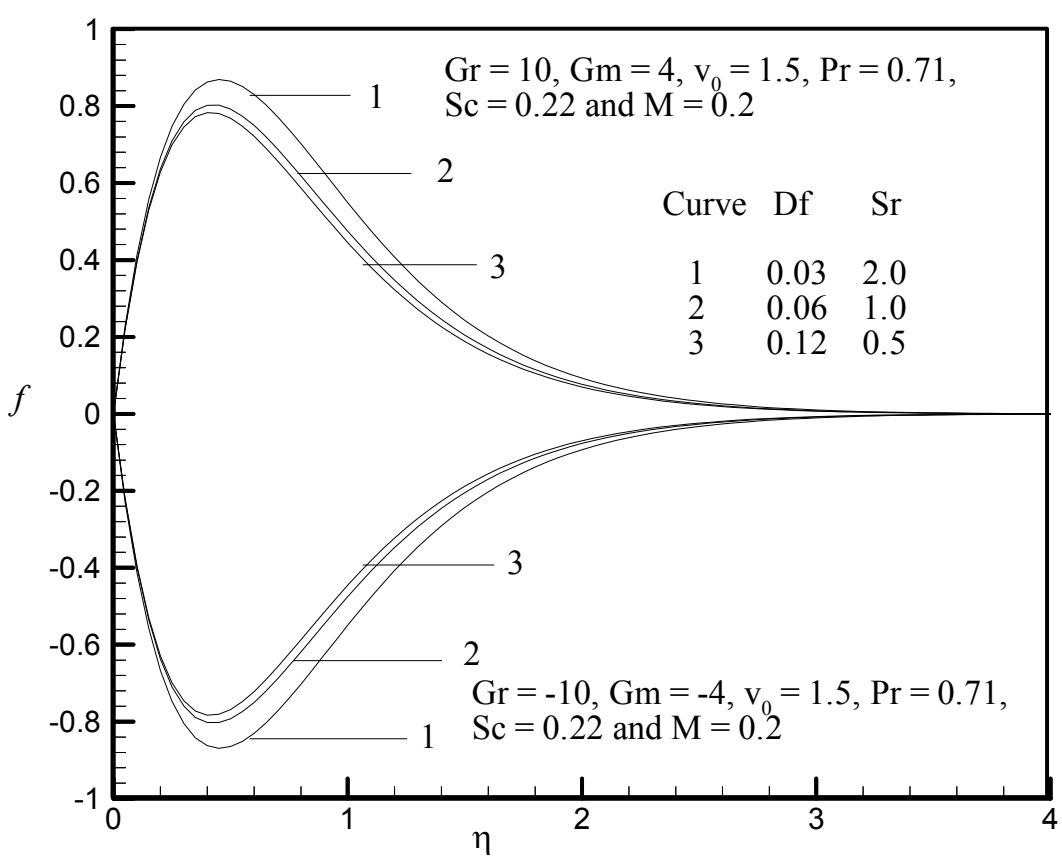

Fig. 2: Velocity profiles due to cooling and heating of the plate for different values of $\mathrm{Sr}$ and Df. 


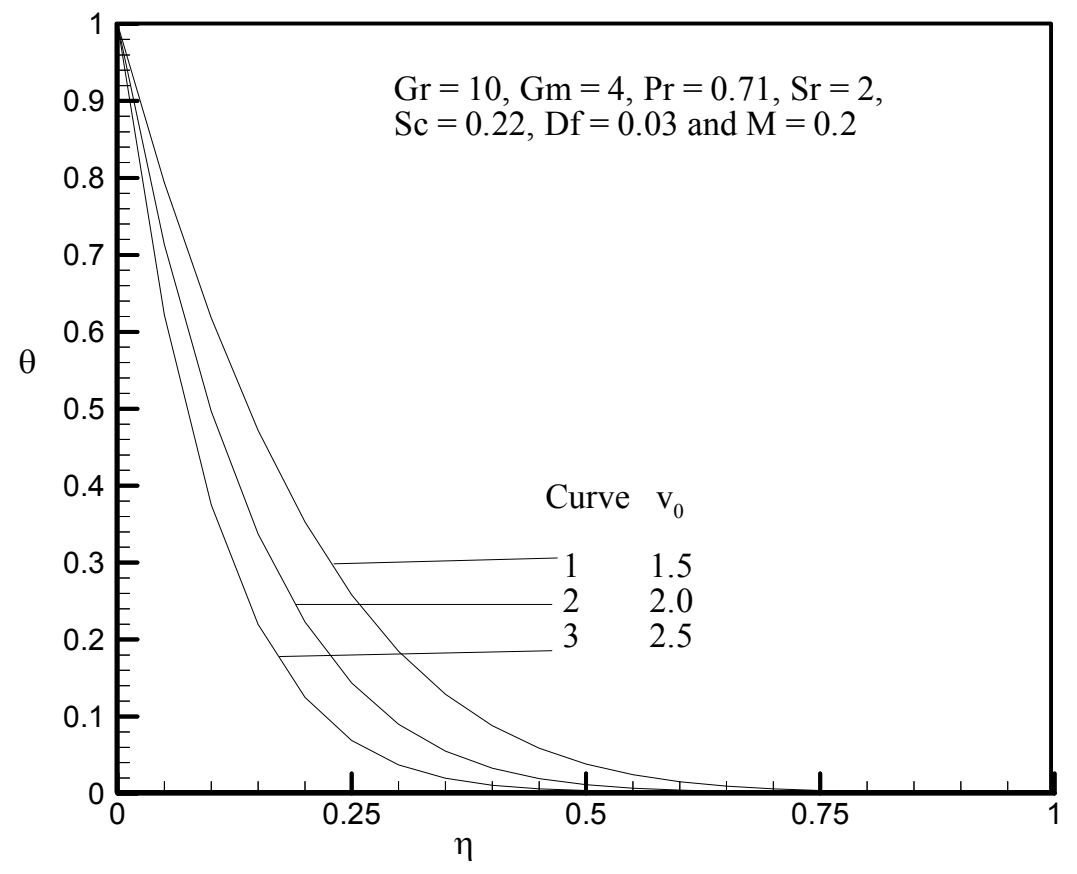

Fig. 3: Temperature profiles due to cooling of the plate for different values of $v_{0}$.

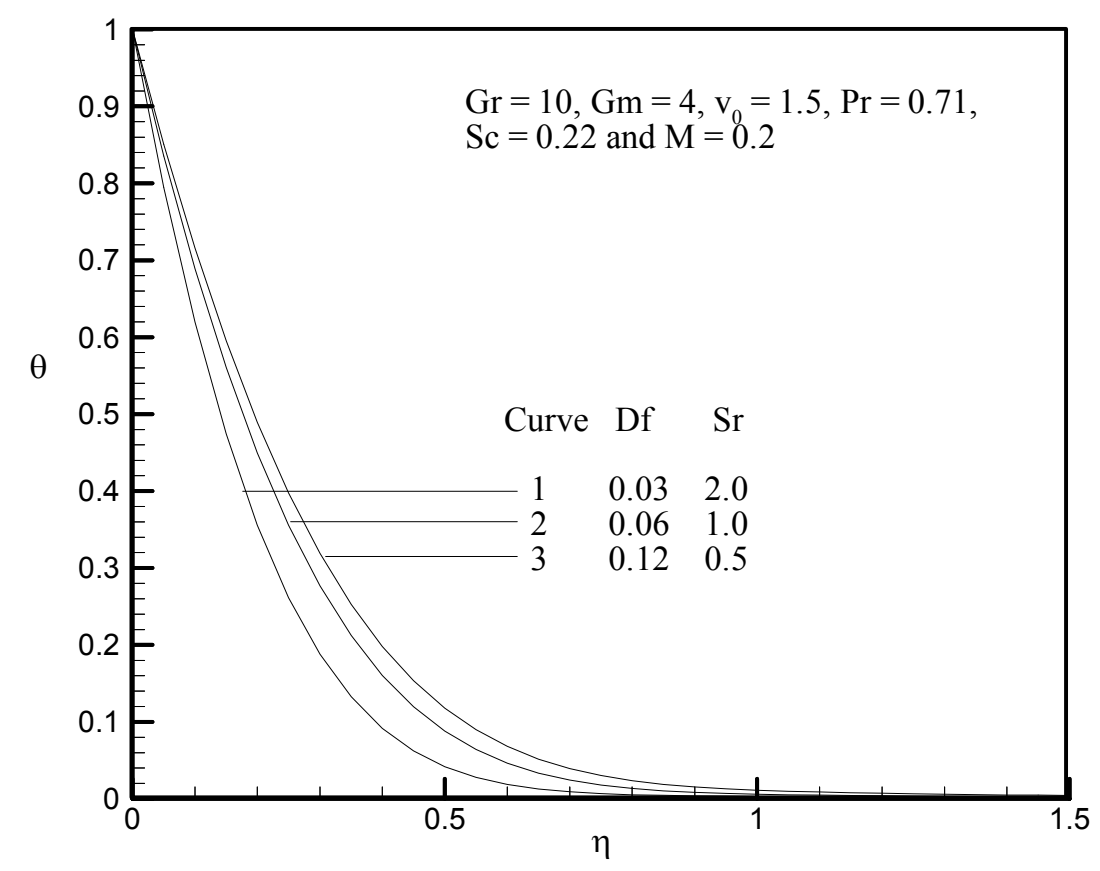

Fig. 4: Temperature profiles due to cooling of the plate for different values of $\mathrm{Sr}$ and $\mathrm{Df}$. 


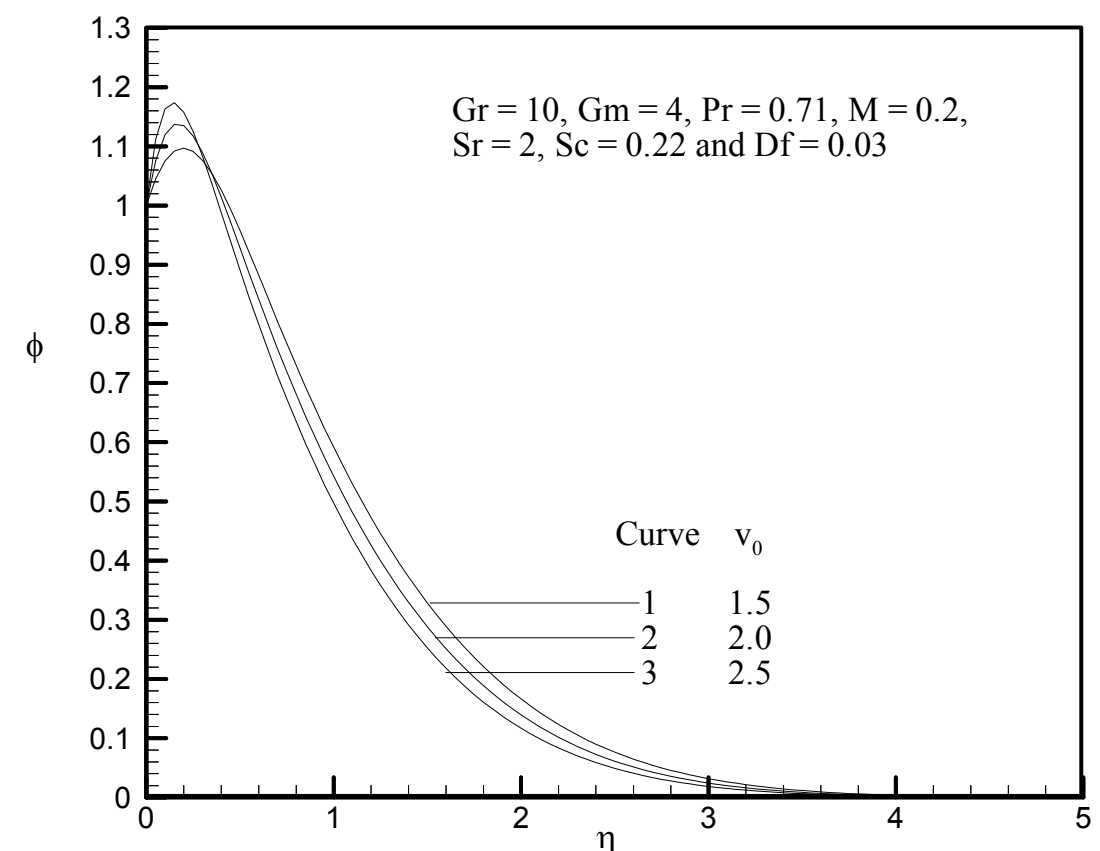

Fig. 5: Concentration profiles due to cooling of the plate for different values of $v_{0}$.

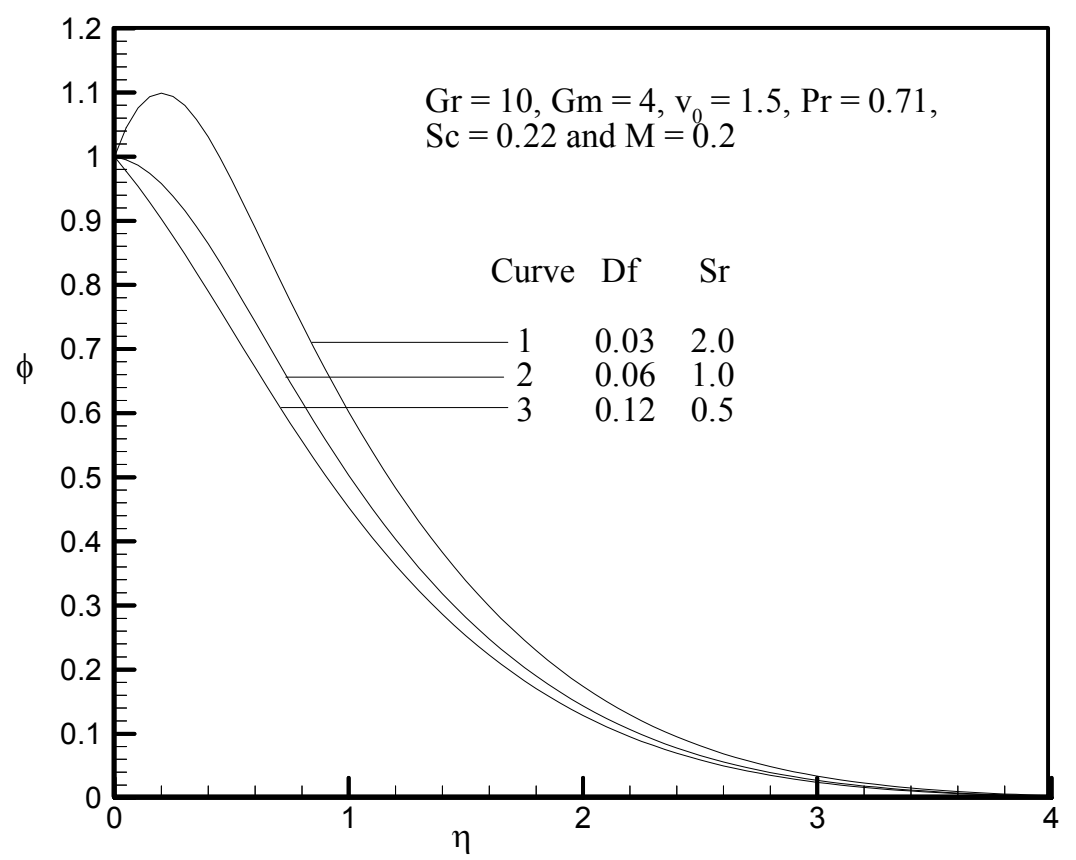

Fig. 6: Concentration profiles due to cooling of the plate for different values of Sr and Df.

Finally, the effects of the above-mentioned parameters on the local skin-friction coefficients, rate of heat and mass transfer are shown in Table 1. These effects are excellent agreement with those seen on the velocity, temperature and concentration profiles. The conclusions and discussions regarding the behavior of the parameters on skin-friction and rate of heat and mass transfer coefficients are self evident from Table 1. 
Table 1: Numerical values of skin-friction coefficients, Nusselt number and Sherwood number for $\operatorname{Pr}=0.71, v_{0}=1.5, M=0.2$ and $S c=0.22$.

\begin{tabular}{|c|l|l|l|l|l|l|}
\hline$G r$ & $G m$ & $D f$ & $S r$ & \multicolumn{1}{|c|}{$C_{f}$} & $N u$ & $S h$ \\
\hline+10 & +4 & 0.03 & 2.0 & 5.123700 & 4.428883 & -1.049408 \\
\hline+10 & +4 & 0.037 & 1.6 & 5.060047 & 3.977430 & -0.531617 \\
\hline+10 & +4 & 0.050 & 1.2 & 5.002257 & 3.622623 & -0.119442 \\
\hline+10 & +4 & 0.075 & 0.8 & 4.952990 & 3.329626 & 0.219757 \\
\hline+10 & +4 & 0.150 & 0.4 & 4.946084 & 3.05512 & 0.505906 \\
\hline+10 & +4 & 0.600 & 0.1 & 5.281809 & 2.631941 & 0.693803 \\
\hline-10 & -4 & 0.03 & 2.0 & -5.123700 & 4.428883 & -1.049408 \\
\hline-10 & -4 & 0.037 & 1.6 & -5.060047 & 3.977430 & -0.531617 \\
\hline-10 & -4 & 0.050 & 1.2 & -5.002257 & 3.622623 & -0.119442 \\
\hline-10 & -4 & 0.075 & 0.8 & -4.952990 & 3.329626 & 0.219757 \\
\hline-10 & -4 & 0.150 & 0.4 & -4.946084 & 3.05512 & 0.505906 \\
\hline-10 & -4 & 0.600 & 0.1 & -5.281809 & 2.631941 & 0.693803 \\
\hline
\end{tabular}

\section{References}

Eckert, E. R. G. and Drake, R. M. (1972): Analysis of Heat and Mass Transfer, McGraw-Hill, New York.

Hasimoto, H. (1957): Boundary layer growth on a flat plate with suction or injection, J. Phys. Soc. Japan, Vol. 12, pp. 68 - 72.

Jha, B. K. and Singh, A. K. (1990): Soret effects on free convection and mass transfer flow in the Stokes problem for an infinite vertical plate, Astrophys. Space Sci., Vol. 173, pp. 251 - 255.

Kafoussias, N. G., Nanousis, N. D. and Georgantopoulos, G. A. (1979): Free convection effects on the Stokes problem for an infinite vertical-limiting surface with constant suction, Astrophys. Space Sci., Vol. 64a, pp. 391 - 399.

Kafoussias, N. G. (1992): MHD thermal-diffusion effects on free-convective and mass transfer flow over an infinite vertical moving plate, Astrophys. Space Sci., Vol. 192, pp. 11 - 19.

Kafoussias, N. G. and Williams, E. M. (1995): Thermal-diffusion and diffusion-thermo effects on mixed free-forced convective and mass transfer boundary layer flow with temperature dependent viscosity, Int. J. Engng. Sci. Vol.33, pp.1369 - 1384.

Nachtsheim, P. R. and Swigert, P. (1965): Satisfaction of the asymptotic boundary conditions in numerical solution of the system of non-linear equations of boundary layer type, NASA TND-3004.

Nanousis, N., Georgantopoulos, G. and Papaioannou, A. (1980): Astrophys. Space Sci., Vol. 70, p. 377.

Sattar, M. A. and Hossain, M. M. (1992): Unsteady hydromagnetic free convection flow with Hall current and mass transfer along an accelerated porous plate with time dependent temperature and concentration, Can. J. Phys., Vol 70, pp. 369 - 374.

Sattar, M. A. (1993): Unsteady hydromagnetic free convection flow with Hall current mass transfer and variable suction through a porous medium near an infinite vertical porous plate with constant heat flux, Int. J. Energy Res., Vol. 17, pp. 1 - 4.

Schlichting, H. (1968): Boundary Layer Theory, $6^{\text {th }}$ Edn, McGraw-Hill, New York.

Soundalgekar, V. M. (1977): Free convection effects on the Stokes problem for an infinite vertical plate, ASME, J. Heat Transfer, Vol. 99, pp. 499 - 501. 